\title{
IDEOLOGIA DE VIDA E MOTIVAÇÃO EMPREENDEDORA
}

\section{Life ideology and entrepreneural motivation}

\begin{abstract}
Andrea Luisa Bozzo
E-mail: andrea.bozzo@uol.com.br

Doutora em Administração pela Universidade Nove de Julho;

Mestra em Controladoria pela Universidade Mackenzie; Empresária.

Endereço para contato: Rua Geneve, 122, apartamento 13C, Mandaqui, 02440-080, São Paulo, São

Paulo, Brasil.

https://orcid.org/0000-0002-0739-9726

Henrique Mello Freitas

E-mail: freitas138@gmail.com

Doutor em Administração pela Université Pierre Mendès-France: Grenoble, Rhône-Alpes, França; Mestre em Ciência da Gestão pela Université Pierre Mendès-France: Grenoble, Rhône-Alpes, França; Professor no Programa de Pós-graduação em Administração da Universidade Nove de Julho.

https://orcid.org/0000-0002-5345-7261
\end{abstract}

Cristina Dai Prá Martens

E-mail: cristinadpmartens@gmail.com

Pós-doutorada no CERAG/UPMF-Université Pierre Mendès-France: Grenoble, França; Doutora em Administração pelo Programa de Pós-graduação em Administração e pela Escola de Administração da Universidade Federal do Rio Grande do Sul;

Professora no Programa de Pós-graduação em Administração da Universidade Nove de Julho. https://orcid.org/0000-0003-0955-9786

Alex De Souza Santana

E-mail: alexsantana.gp@gmail.com

Mestre em Administração pela Universidade Nove de Julho; Doutorando em Administração na Universidade Nove de Julho; Gerente de Projeto na Empresa Adistec Informática LTDA. https://orcid.org/0000-0001-9675-9115

Artigo recebido em 4 de setembro de 2018. Aceito em 5 de agosto de 2019. 


\section{Resumo}

O empreendedorismo por estilo de vida tem sido reconhecido como um dos impulsionadores para o surgimento de novas empresas. A maioria das pesquisas nessa temática concentramse nos aspectos resultantes do comportamento empreendedor por estilo de vida, no entanto, observou-se a existência de uma lacuna a ser explorada no que se refere à identificação dos fatores que motivam o comportamento. Tal oportunidade de estudo instigou a seguinte questão de pesquisa: quais são os valores motivadores dos empreendedores por estilo de vida? Portanto, o presente artigo utilizou-se de conceitos originados na área da Psicologia, especificamente do modelo hierárquico de motivação intrínseca e extrínseca como maneira de fornecer embasamento para a investigação sobre os motivadores individuais. Desse modo, identificou-se que os empreendedores por estilo de vida são orientados pela motivação intrínseca (pois a atividade em si é fornecedora de uma recompensa percebida), ou seja, eles são estimulados pelos aspectos de satisfação e prazer em prol de uma melhoria na sua qualidade de vida. $O$ estudo de natureza qualitativa é baseado em entrevistas presenciais, as quais foram realizadas com três empreendedores, contando, para tal, com o auxílio de um roteiro semiestruturado. Os dados resultantes das entrevistas foram submetidos à análise de conteúdo. Este estudo contribui gerencialmente com a revelação de que o empreendedorismo por estilo de vida oferece oportunidades de engajamento com consumidores que compartilham valores comuns.

Palavras-chave: Empreendedorismo. Motivação. Ideologia de vida.

\section{Abstract}

Lifestyle entrepreneurship has been recognized as one of the drivers for the emergence of new businesses. Most of the research on this topic focuses on the aspects resulting from entrepreneurial behavior by lifestyle, however, there was a gap to be explored with regard to the identification of the factors that motivate the behavior. Such a study opportunity instigated the following research question: What are the motivational values of entrepreneurs by lifestyle? Therefore, the present article uses concepts originated in the area of Psychology, specifically the hierarchical model of intrinsic and extrinsic motivation as a way to provide grounding for research on individual motivators. Thus, it has been identified that lifestyle entrepreneurs are driven by intrinsic motivation (since the activity itself provides a perceived reward), that is, they are stimulated by the aspects of satisfaction and pleasure in favor of an improvement in their quality of life. The qualitative study is based on face-to-face interviews, which were carried out with three entrepreneurs, counting with the help of a semistructured script. The data resulting from the interviews were submitted to content analysis. This study contributes managerially to the revelation that entrepreneurship by lifestyle offers opportunities for engagement with consumers who share common values.

Keywords: Entrepreneurship. Motivation. Life Ideology.

\section{INTRODUÇÃO}

Empreender como estilo de vida é uma das recentes vertentes que trata o empreendedor em sua individualidade e que aborda a perspectiva do negócio voltado para a paixão pela atividade, e não apenas visando apenas ao lucro (Peters, Frehse, e Buhalis, 2009; Ribeiro \& Krakauer, 2016). Em uma noção funcionalista de empreendedorismo, valorizam-se os resultados financeiros e econômicos da acumulação de riqueza (ou seja, o lucro) e a criação 
de emprego como o supremo, ou até, muitas vezes, como o único objetivo (Welter, Baker, Andretsch, \& Gartner, 2017). Contudo, hoje há uma perspectiva emergente que tem discutido o fato de que nem todos os indivíduos buscam esse objetivo de maximização do lucro, mas, antes disso, escolhem uma atividade, um negócio que se adapte ao seu estilo de vida atual ou ao pretendido (Gomez-Velasco \& Saleilles, 2007). Ainda assim, essa é uma vertente pouco explorada no entendimento do empreendedorismo enquanto estilo de vida (Valente, 2018).

As pesquisas existentes sobre empreendedorismo e estilo de vida geralmente se referem a empreendedores com o objetivo de realizar um equilíbrio entre o seu estilo de vida particular e as suas necessidades econômicas, familiares e sociais (Murry, 2002; Domenico, 2003). Em outras palavras, tratam-se de empreendedores do estilo de vida estreitamente alinhados com seus valores pessoais, suas crenças, seus interesses e suas paixões (Henricks, 2002); empreendedores centrados em uma visão que coloca necessidades e preferências pessoais à frente do crescimento e da maximização do lucro (Getz \& Carlsen, 2005); que visam maior qualidade de vida aos funcionários, aos clientes, à comunidade (Marcketti, 2006) e à identidade do estilo de vida do empreendedor (Bredvold \& Skålén, 2016).

No que diz respeito a essa temática, observou-se uma lacuna teórica sobre a caracterização do empreendedorismo por estilo de vida, pois, embora existam pesquisas sobre os fatores motivacionais para entender o grau em que um indivíduo é orientado por questões de estilo de vida e/ou questões financeiras, poucos estudos aprofundaram as práticas individuais que definem esse conceito (Allardyce, 2015). Com base nessa constatação, esta pesquisa investiga a seguinte questão: quais são os valores motivadores de empreendedores por estilo de vida? Ao buscar respondê-la, objetiva-se verificar quais as tendências motivacionais dos empreendedores por estilo de vida.

Este trabalho contribui para a literatura da área ao propor a aplicação de uma diferente análise para mapear os motivadores do empreendedorismo por estilo de vida. Mais especificamente, analisaram-se casos de empreendimentos por estilo de vida, por meio do modelo hierárquico de motivação intrínseca e extrínseca, proposto por Vallerand (1997). Este estudo preenche uma lacuna na literatura, na medida em que os achados revelam que esses empreendedores por estilo de vida são orientados pela motivação intrínseca. Em outras palavras, quando a própria atividade fornece a recompensa, isto é, quando o indivíduo se sente motivado para a execução de uma tarefa, estimulado pelos aspectos de satisfação e prazer, em prol de uma melhoria na sua qualidade de vida. Como resultado, verifica-se que os motivadores e as consequências relacionados ao empreendedorismo por estilo de vida se manifestam mais claramente no nível situacional. 


\section{REVISÃO DA LITERATURA}

Pesquisadores definiram os empreendedores de estilo de vida como indivíduos que possuem e operam empresas estreitamente alinhadas aos seus valores pessoais, seus interesses e suas paixões. No entanto, ainda existem vários fatores do empreendedorismo por estilo de vida que merecem ser explorados, como mencionados anteriormente. Para tanto, esta seção, inicialmente, faz uma apresentação do empreendedorismo por estilo de vida e, na sequência, aborda o modelo hierárquico de motivação intrínseca e extrínseca.

\subsection{EMPREENDEDORISMO COMO ESTILO DE VIDA}

O empreendedorismo como estilo de vida trata o indivíduo empreendedor, observando a sua paixão pela atividade (Ribeiro \& Krakauer, 2016). Os empreendedores por estilo de vida são motivados por questões de realização pessoal, talvez mais do que por motivações puramente lucrativas (Allardyce, 2015). Eles são associados a uma ideologia de vida, na qual a motivação empreendedora encontra a satisfação em conquistas como, por exemplo, passar mais tempo com familiares e amigos, aumentar a consciência de que a vida é significativa e gerenciável (Burns, 2001).

O equilíbrio entre vida profissional e pessoal é um dos principais desafios enfrentados pelos empreendedores situados nessa área (Murry, 2002). Em sua pesquisa, Murry (2002) traz o desejo do empreendedor de fazer do seu estilo de vida uma extensão do negócio, sugerindo que a balança do lado comercial e pessoal geralmente aumenta a consciência de que a vida é significativa e gerenciável. Além da satisfação pessoal, Etzioni (1996) enfatiza que o empreendedorismo também pode melhorar o bem-estar do desenvolvimento da comunidade, identificando os empreendedores comunitários como membros visíveis da comunidade, representando partes importantes da construção da comunidade e um elemento poderoso nos processos de mudança social.

A tomada de decisão de se tornar empreendedor pode acontecer por acaso, em razão de afinidades pessoais, fatores externos, ambientais e sociais, ou ainda, do conjunto de todos esses fatores (Moore, 1986). Nessa decisão, as idiossincrasias das pessoas devem ser consideradas, assim como sua personalidade, suas atitudes e suas emoções, além de suas crenças e suas predisposições (Bergamini, 1997).

A motivação empresarial modifica a relação entre a integração, o trabalho, a vida e o equilíbrio entre o trabalho e a vida, de modo que os donos de negócios orientados para o estilo de vida desfrutem de níveis mais elevados de equilíbrio entre o trabalho e a vida do que os orientados a negócios ( $L i, M i a o, Z$ hao, \& Lehto, 2013). A compreensão do 
empreendedorismo, considerando as ações e as interações do empreendedor com o contexto no qual ele está inserido desenvolve uma outra perspectiva do fenômeno a partir de grupos específicos (Shane \& Venkataraman, 2000). Nessa perspectiva, Li et al. (2013) desenvolveram um quadro conceitual para entender o impacto das características da fronteira trabalhovida e a motivação empresarial no equilíbrio vida-trabalho.

Os empreendedores de estilo de vida priorizam a satisfação de passar bons momentos com a família e os amigos (Henderson, 2002). Por causa de seu objetivo, eles são focados em equilibrar as demandas do negócio e o convívio com a família (Murry, 2002), aumentando a consciência de que a vida é significativa e administrável. A satisfação pessoal no empreendedorismo pode melhorar o bem-estar no nível comunitário (Etzioni, 1996). Para esse autor, o desenvolvimento e a manutenção da qualidade de vida exigem atenção aos valores compartilhados em todos os níveis da estrutura social da comunidade: empresas, famílias, governo, religião, entre outros. Assim, os empreendedores de estilo de vida, embora não estejam diretamente focados na mudança social, compartilham valores semelhantes aos dos setores comunitários (Henricks, 2002).

O entendimento do impacto das características da fronteira trabalho-vida e a motivação empresarial oferecem algumas implicações importantes para alcançar o equilíbrio entre o trabalho e a vida (Marcketti, 2006). Os empreendedores devem desenvolver estratégias que permitam a fronteira entre o trabalho e a vida pessoal ( $\mathrm{Li}$ et al., 2013). Jaouen e Lasch (2013) concluíram que muitos empreendedores são motivados por razões não financeiras ou pessoais e desejam apenas a satisfação e a subsistência, e não necessariamente o crescimento empresarial. Esses autores, em seu estudo, destacaram que o crescimento empresarial não é um caminho necessário para a sobrevivência e o sucesso.

\subsection{MODELO HIERÁRQUICO DE MOTIVAÇÃO INTRÍNSECA E EXTRÍNSECA}

Algumas pesquisas dividem a motivação em duas classes distintas. A primeira está relacionada ao comportamento propriamente dito, visando prazer e/ou satisfação com a atividade desenvolvida, sendo tratada como motivação intrínseca. A segunda, por sua vez, relaciona-se ao alcance de determinado objetivo, ao recebimento de recompensa/retorno ou mesmo para evitar algum tipo de punição, sendo tratada então como motivação extrínseca (Deci \& Ryan, 1980). Portanto, uma vez que o empreendedorismo por estilo de vida está mais relacionado ao equilíbrio entre trabalho e vida, bem como à satisfação com a atividade em si, acredita-se que os motivadores do estilo de vida tendam a pesar mais para a motivação intrínseca.

A motivação intrínseca, como apresentada, geralmente se refere à realização de uma atividade para si mesmo, ao prazer e à satisfação derivados nesse processo de participação 
(Vallerand, 1997). Esse autor exemplifica a diferença da motivação intrínseca e extrínseca da seguinte maneira: se perguntássemos às pessoas que estão intrinsecamente motivadas com relação ao trabalho, se continuariam trabalhando caso ganhassem na loteria, provavelmente diriam que sim. Isso aconteceria porque essas pessoas não estão trabalhando principalmente para ganhar dinheiro, mas para sentirem satisfação. Elas se concentram no processo, não nos resultados. Por outro lado, as pessoas motivadas extrinsecamente fazem uma atividade para alcançar resultados, como receber o pagamento. Se elas puderem alcançar esses objetivos mais facilmente, terão prazer em fazê-lo. Assim, pessoas motivadas extrinsecamente provavelmente parariam de trabalhar se ganhassem na loteria.

Tanto a motivação intrínseca quanto a extrínseca podem se apresentar em três níveis hierárquicos gerais: nível global, nível contextual e nível situacional. Nessa hierarquia, a motivação global afetará a motivação contextual e a motivação contextual afetará a motivação situacional. Motivação em nível global refere-se a uma orientação motivacional geral para interagir com o ambiente de forma intrínseca ou extrínseca, ou seja, às diferenças individuais relativamente duradouras, podendo ser visto o nível global como representativo da tradição da personalidade na motivação intrínseca e extrínseca. A motivação contextual refere-se à orientação motivacional usual para um contexto específico, sendo tal contexto referente a uma esfera distinta da atividade humana, como a educação, o lazer, o trabalho, etc. A motivação situacional refere-se àquela sensação que os indivíduos experimentam quando estão atualmente engajados em uma atividade, ou, em outras palavras, refere-se ao aqui e agora da motivação (Vallerand, 1997).

Sobre os determinantes da motivação, consideram-se os fatores sociais afetando cada um dos três níveis hierárquicos. Assim, temos fatores globais afetando o nível global, fatores contextuais afetando o nível contextual e fatores situacionais afetando o nível situacional. Cabe dizer, ainda, que o impacto dos fatores sociais na motivação é mediado pela percepção de competência (interagindo efetivamente com o ambiente), autonomia (sentir-se livre para escolher o curso de ação) e parentesco (sentir-se conectado a outros) em cada um dos três níveis hierárquicos. Por fim, as consequências da motivação podem ser cognitivas, afetivas ou comportamentais também em cada um dos níveis hierárquicos (Vallerand, 1997).

\section{MÉTODO}

Uma pesquisa qualitativa foi realizada com uma amostra propositalmente selecionada de empreendedores por estilo de vida. Os entrevistados foram escolhidos por diversas razões. Em primeiro lugar, por serem exemplos de empreendimentos com empreendedores por estilo de vida que operam empresas alinhadas com seus valores pessoais, suas crenças e suas paixões. Essa definição envolveu a principal motivação para iniciar a empresa. Em segundo 
lugar, os empreendedores de estilo de vida escolhidos iniciam seus negócios como uma estratégia de vida para alcançar a autorrealização (Buttner \& Moore, 1997), e não apenas visando ao desenvolvimento de uma carreira.

Neste trabalho utilizou-se de forma simplificada os elementos da análise de conteúdo a partir de uma entrevista semiestruturada, identificando as ideias-chave representativas do objetivo delimitado para esta investigação. A análise de conteúdo, segundo Bardin (2009), é:

Um conjunto de técnicas de análise das comunicações visando obter por procedimentos sistemáticos e objetivos de descrição do conteúdo das mensagens indicadores (quantitativos ou não) que permitam a inferência de conhecimentos relativos às condições de produção/recepção (variáveis inferidas) destas mensagens.

\subsection{UNIDADE DE ANÁLISE}

Os dados para o estudo foram coletados por meio de três entrevistas com empreendedores escolhidos de maneira intencional para o estudo de empreendedorismo por estilo de vida. Foram entrevistados proprietários, que trabalham na gestão e operação do negócio. Múltiplos informantes mitigam os vieses dos sujeitos (Golden, 1992) e levam a um enriquecimento de um modelo mais elaborado (Johnson, 2001), além de ajudarem a explicar melhor o papel do estilo de vida no processo de empreender.

\subsubsection{Características dos entrevistados}

Torna-se importante explicar que as identidades foram trocadas para garantir - anonimato dos sujeitos, por não se ter a autorização de divulgação dos nomes dos entrevistados. Sobre os trabalhos desses indivíduos, o primeiro é empreendedor proprietário de um restaurante vegano, o segundo é empreendedor proprietário de uma loja de artigos religiosos, e a terceira é empreendedora proprietária de um empório que comercializa alimentos típicos e naturais. Todos esses empreendedores têm como característica comum a motivação em empreender por meio de uma atividade associada à qualidade de vida. Esse foi o principal fator que conduziu à abertura das suas respectivas empresas. Todos eles atuam no Estado de São Paulo e seus perfis demográficos são mostrados na Tabela 1: 
Tabela 1

Características demográficas dos empresários de estilo de vida entrevistados

\begin{tabular}{cccccc}
\hline Nome & Idade & $\begin{array}{c}\text { Formação } \\
\text { acadêmica }\end{array}$ & Tipo de negócio & $\begin{array}{c}\text { Ano de início } \\
\text { do negócio }\end{array}$ & $\begin{array}{c}\text { Número de } \\
\text { funcionários }\end{array}$ \\
\hline João & 39 & Cinema & Restaurante Vegano & 2016 & 4 \\
André & 45 & Administração & Casa de artigos religiosos & 2011 & 0 \\
Sofia & 47 & Direito & Empório de produtos naturais & 2018 & 2 \\
\hline
\end{tabular}

Nota. Os novos foram mudados.

\subsubsection{Entrevistado 1-Proprietário de um restaurante vegano}

João tem 39 anos, possui formação superior em cinema e atuou profissionalmente como cineasta. Anteriormente ao seu negócio, tinha um blog de gastronomia. $\mathrm{O}$ empreendedor entrevistado não tinha experiência anterior no segmento de restaurantes. Para iniciar o seu negócio, buscou ajuda de amigos que já possuíam um restaurante vegano. Ele acredita que a sua experiência em marketing e a sua habilidade em lidar com o público foram fundamentais para planejar cada ideia do início do negócio. João disse que sempre adotou um estilo de vida voltado ao veganismo e que tinha como objetivo de vida ter o seu próprio negócio para disseminar esse estilo. Para ele, o restaurante é uma maneira de proporcionar aos seus consumidores uma melhor qualidade de vida.

\subsubsection{Entrevistado 2-Proprietária de uma casa de artigos religiosos}

André tem 45 anos, possui formação superior em Administração e pós-graduação em Gestão Comercial. Sua carreira foi desenvolvida em grandes empresas da área comercial. Apesar de ter obtido êxito profissional, o principal motivo que o fez abrir mão da carreira foi a falta de tempo que tinha para dedicar à sua família. Como representante comercial, afirmou que possuía uma rotina de inúmeras viagens e que isso desgastava consideravelmente sua vida pessoal. Ele afirmou também que realizou seu sonho de ter no seu negócio uma extensão das suas crenças religiosas e o desejo de estar mais presente na rotina de sua família, proporcionando uma melhor qualidade de vida a todos.

\subsubsection{Entrevistada 3-Proprietária de um empório de produtos naturais}

Sofia tem 47 anos, possui formação em Direito e uma carreira executiva de mais de 20 anos em multinacionais. Tinha como sonho pessoal trabalhar em um ambiente no qual pudesse 
ter uma rotina mais tranquila. Ela idealizava poder trabalhar sem as grandes pressões que seu cargo de Diretora exigia e que consumiam não apenas seu dia, mas acabavam invadindo sua vida pessoal. Para ela, os anos foram passando e percebeu que sua história se resumia em memórias apenas do trabalho. Ela afirmou que abriu mão de casar e de ter filhos, pois o trabalho acabava consumindo praticamente todo o seu tempo. Então, inspirada em amigos que já tinham migrado de uma carreira de sucesso para um empreendimento que permitia conciliar o trabalho e a vida pessoal, decidiu iniciar seu próprio negócio. Ela justificou sua escolha por poder fazer do seu negócio um ambiente de amizade com seus consumidores e afirmou que seu trabalho é uma extensão do seu convívio em família, pois cada detalhe da sua loja tem traços de personalidade da sua família, inclusive o nome do empório é uma homenagem ao seu pai. Ela sente-se orgulhosa de poder afirmar que seu negócio lhe trouxe uma melhor qualidade de vida.

\subsection{PROCEDIMENTOS DE COLETA DE DADOS}

O guia de entrevista semiestruturada foi dividido em temas e contou com 21 questões. Assim, questionaram-se os empreendedores a respeito da história das suas empresas e das motivações para essa criação, além disso, perguntou-se também a respeito da história pessoal do proprietário e das aspirações para a vida pessoal, sua experiência anterior, sua formação e suas características pessoais. Também foram abordados aspectos como perfis dos clientes, maneira de coordenação e gerenciamento e intenções de desenvolvimento ou crescimento do negócio.

As entrevistas foram presenciais e tiveram uma duração média de 40 minutos. Todas foram gravadas e transcritas. Trechos dos depoimentos dos empreendedores foram inseridos neste trabalho exatamente da mesma maneira em que a entrevista ocorreu. Um aspecto muito importante da pesquisa foi a captura de trechos-chave do discurso dos entrevistados, de forma que se conseguisse mapear esses pontos no modelo hierárquico de motivação intrínseca e extrínseca, os quais são explorados na seção seguinte deste artigo.

\section{RESULTADOS}

Nesta seção são apresentadas as informações coletadas nas entrevistas com os proprietários/empreendedores por estilo de vida. 


\subsection{QUALIDADE DE VIDA}

A melhoria da qualidade de vida do empreendedor e a percepção do empreendedorismo como fornecimento de uma satisfação aos consumidores foram unânimes entre os entrevistados. Os empreendedores descobriram no seu negócio uma forma de melhoria de qualidade de vida e têm nos seus objetivos comerciais a priorização da qualidade de serviço como forma de gerar lucros. Além disso, esses empreendedores consideram a qualidade de vida a principal razão de empreender. Ao oferecerem serviços adequados ao perfil de seus consumidores, vislumbram oportunidades de engajamento com os consumidores que compartilham valores comuns. Esses empreendedores consistentemente mencionaram as oportunidades de crescimento em favor do cumprimento de compromissos com seus consumidores. Uma vez que os negócios alcançaram algum sucesso, eles notaram uma melhoria da própria qualidade de vida e viram seu negócio afetar positivamente seus consumidores. Esses benefícios destacaram as diferenças fundamentais de empreendedores de estilo de vida.

Nas entrevistas foram abordadas as razões que motivaram a realização do empreendimento. Foi relatado pelos proprietários que ter no seu negócio uma melhor qualidade de vida favorece a criação de um ambiente de bem-estar e harmonia com as pessoas, fator essencial para a satisfação pessoal. Esses empreendedores relatam a satisfação de promover um ambiente agradável por estar em conformidade com suas características pessoais. Para eles, é preciso ter no seu negócio um espelho das suas crenças pessoais. Essa motivação situacional refere-se à motivação pessoal de estarem engajados em uma atividade que lhes proporciona autorrealização (Vallerand, 1997).

Uma motivação situacional comum entre os entrevistados é conseguir que seus clientes tenham uma experiência de compra customizada e possam ter suas expectativas atendidas. O proprietário do restaurante vegano, por exemplo, comentou que sua maior satisfação é poder oferecer para seus consumidores uma alternativa de consumo de alimentos mais saudáveis de acordo com suas crenças. Nas suas palavras, ele destacou um exemplo de como isso acontece:

A gente já teve caso de pessoas que estiveram aqui e nunca tinham comido nada vegano e voltaram e disseram que depois que conheceram o restaurante fizeram uma semana vegana em casa, foram pesquisar na internet, fizeram receitas. Acho que a maior motivação é que as pessoas vêm aqui e querem mudar sua postura diante da alimentação. Eu acho que é isto. Você poder colocar em prática seus sonhos, saber que tem limites, mas aos poucos você pode ir colocando em prática ... (Informação verbal, 10 de julho de 2017). 
Já o entrevistado da casa de artigos religiosos disse tentar quebrar alguma estranheza das pessoas com o tema, contando sua própria experiência como praticante da religião espírita. Dessa maneira, ele consegue desenvolver uma situação que vai além da comercialização de artigos religiosos. Ele comenta que sua satisfação com os consumidores é poder dar uma palavra de conforto e perceber que cada cliente sai da sua loja mais animado do que quando chegou.

Esse empreendedor disse ainda que muitos clientes retornam na loja simplesmente para agradecer pelas palavras de conforto. Ele ressaltou que sempre tem a preocupação de saber o limite para poder ajudar de alguma forma, mas sem querer se intrometer na vida pessoal dos seus clientes. Essa situação de interação com os consumidores para o entrevistado cria laços e principalmente ajuda na divulgação da sua loja por meio de indicação de clientes que têm satisfação em levar amigos em seu estabelecimento para conhecer o seu trabalho.

\subsection{EXPERIÊNCIAS COMO PROFISSIONAIS}

Sobre as suas principais habilidades como empreendedor, o proprietário do restaurante vegano explicou que seu maior desafio é pensar como empreendedor. Isso para ele significa ter senso de administração e não perder o foco de toda a ideologia, como ele comentou:

\footnotetext{
Isto é um negócio, então você tem que ter uma cabeça voltada para números, você tem que ter gestão do negócio. Acho que isto é um dos pontos principais. $O$ segundo ponto é ser muito honesto com aquilo que você está fazendo, ser honesto com seu público, com você e entregar para o cliente aquilo que você acredita também. Sempre fazer aquilo que as pessoas não vejam que você é uma fraude, que elas compreendam a sua ideia porque elas enxergam você como um exemplo. Ser o espelho daquilo que você faz. E o terceiro ponto é ter muita persistência mesmo. (Informação verbal, 10 de julho de 2017).
}

Sobre a área de negócios, o proprietário da casa de artigos religiosos relatou que, em razão da sua formação como administrador, ele não teve grandes dificuldades para se tornar um empreendedor:

\footnotetext{
Eu consigo aplicar o conhecimento que eu adquiri ao longo dos anos e ver os resultados, por ser um comércio tem que ter lucro. Montei a loja para ter resultados, no entanto, poder conciliar a religião, a família e aplicar a experiência pessoal e ver que dá resultado é a minha maior realização. Estou há oito anos neste negócio e meu conselho para quem está iniciando em um negócio é ter uma vida pessoal organizada, pois o empreendimento não vai dar um retorno rápido. Então, você tem que investir, organizar as contas e ter uma reserva financeira inicial. Trabalhar com bastante afinco, amor e carinho que, com o tempo, você vai tendo um retorno. As pessoas começam a lhe
} 
retribuir pelo bom atendimento. A concorrência neste caso não é um problema, pois com um bom atendimento, não "empurrando" produtos ou serviços desnecessários para seu cliente, ele vai sentir em você credibilidade e vai voltar. (Informação verbal, 19 de abril de 2018).

Já o conselho da proprietária do empório para alguém que está pensando em iniciar um negócio baseado em sua ideologia de vida é buscar parcerias. Para ela, buscar aliados é fundamental, conforme seu próprio exemplo:

Como eu não tinha experiência no comércio e queria realizar meu sonho de empreender, contei com a ajuda de um amigo do segmento de supermercados. Hoje ele é meu sócio e completa o meu "lado comerciante". Nós nos completamos, eu com minha motivação de poder me realizar fazendo o que mais gosto, ou seja, o convívio com pessoas e a satisfação dos meus clientes, e meu sócio com sua experiência empreendedora. Tenho um exemplo interessante de experiência dos meus consumidores: um cliente queria um produto oriental, eu peguei o contato dele e, assim que o produto chegou, eu o avisei. Ele ficou muito surpreso e no mesmo dia já encomendou mais cinco unidades. Nossa! Eu fiquei muito feliz com a reação deste cliente! (Informação verbal, 20 de abril de 2018).

Quanto à pergunta: "onde você se vê, e a sua empresa, em cinco anos?" O proprietário do restaurante vegano respondeu o seguinte:

A gente gostaria de expandir para um projeto maior, talvez de um hostel, um espaço maior, onde seja possível receber pessoas para ficar mais tempo, ter um espaço maior para plantar. Um lugar onde as pessoas tenham acesso a uma vivência mais profunda. Isto é uma ideia que a gente ainda vai amadurecer, mas a ideia seria isso, tornar o negócio maior, com uma experiência mais completa, onde as pessoas possam passar o dia, hospedar-se. (Informação verbal, 10 de julho de 2017).

Também sobre o futuro dos negócios, o proprietário da loja de artigos religiosos relatou:

Eu vivo cada dia do meu negócio, estou bem feliz com minha rotina e com a possibilidade de conciliar o trabalho com o convívio familiar. Sinto-me um privilegiado em poder passar o dia trabalhando ao lado da família e convivendo com clientes que posso chamar de amigos. (Informação verbal, 19 de abril de 2018).

Ele complementou seu discurso dizendo que, para o futuro, espera colher frutos dessa interação família/negócio e continuar ajudando as pessoas que procuram no seu negócio mais do que apenas o consumo de mercadorias. 
A proprietária do empório explicou que, com relação ao futuro, hoje ela está vivendo um sonho. Para ela, sua vida mudou para muito melhor. Por mais de 20 anos atuou como Executiva em uma multinacional e praticamente não atendeu à sua vida pessoal. Agora ela diz estar vivendo plenamente sua vida pessoal e profissional. Faz do seu trabalho uma satisfação pessoal e quer muito que nos próximos anos possa contar para amigos e familiares que o seu negócio foi a melhor realização da sua vida pessoal, e uma mudança positiva na sua qualidade de vida. Ela finalizou sua fala mencionando que espera para o futuro servir de exemplo para outras pessoas que decidam conciliar o negócio com a realização pessoal voltada à qualidade de vida.

Com as entrevistas, evidenciou-se que a principal motivação dos empreendedores é o fato de o seu negócio ser uma oportunidade de melhorar sua qualidade de vida pessoal, o que precede a busca apenas de lucros. Os entrevistados frisam sua satisfação em empreender em um negócio que os completa e se sentem privilegiados por isso. Durante as entrevistas, identificou-se a manifestação da motivação intrínseca referente à realização de uma atividade para si mesmo, assim como ao prazer e à satisfação derivados dessa atividade (Deci \& Ryan, 1980). Essa motivação intrínseca está no próprio processo da atividade, o que mostra, em outras palavras, que o foco principal está no processo de realizar algo (Vallerand, 1997).

\section{DISCUSSÃO E CONSIDERAÇÕES FINAIS}

No início deste artigo sugeriu-se que o debate sobre a importância das motivações para o empreendedorismo deveria reconhecer que elas são multifacetadas. Este estudo forneceu uma visão sobre as opções de carreira empreendedora por estilo de vida e estabeleceu uma conexão entre empreendedorismo e qualidade de vida. $O$ objetivo deste estudo foi investigar se os empreendedores por estilo de vida melhoraram a sua qualidade de vida pessoal por meio do modelo hierárquico de motivação intrínseca e extrínseca, como proposto por Vallerand (1997).

No topo do nível hierárquico da motivação, pôde-se verificar que os entrevistados possuem uma motivação intrínseca para o empreendedorismo. Verificou-se que eles estão inseridos em um grupo social de empreendedores e observou-se também o papel dos fatores mediadores: a busca por qualidade de vida, visto que os entrevistados utilizam de suas experiências para vislumbrar novas oportunidades de realização pessoal. Por fim, suas relações mostraram que eles oferecem oportunidades de engajamento com seus consumidores, com os quais compartilham valores comuns. Assim, compreendeu-se que esses empreendedores por estilo de vida priorizam a qualidade de serviço como forma de gerar lucros.

Ainda seguindo o que propõe o modelo hierárquico de motivação intrínseca e extrínseca, percebeu-se que essa motivação afeta diretamente a motivação contextual, ou 
seja, a realização do comportamento empreendedor em si. Contudo, a partir desta pesquisa, não foi posssível supor que o estilo de vida exerça algum tipo de influência no nível contextual, pois os entrevistados que participaram deste estudo já possuíam experiências profissionais anteriores que não estavam relacionadas aos seus estilos de vida e/ou às suas crenças.

Apesar disso, quando se analisou o nível situacional, ficou mais evidente o fato de que o estilo de vida teria influenciado o engajamento nos empreendimentos propriamente ditos. Nesse nível, por fim, manifestam-se como consequências das decisões dos empreendedores os seus sentimentos de satisfação por estenderem sua ideologia a uma forma de negócio que contribui para o bem-estar de seus consumidores, assim como para a motivação e a satisfação deles. Em suma, trata-se muito mais da importância da qualidade de vida do que dos retornos financeiros em si, ou seja, o reflexo de uma motivação muito mais intrínseca, conforme se esperou identificar. Essa investigação permitiu verificar, portanto, que o empreendedorismo por estilo de vida é caracterizado por motivações intrínsecas do indivíduo, claramente destacáveis no discurso desses empreendedores.

As motivações deles são oriundas da satisfação que a atividade lhes proporciona. $E$ a motivação no empreendedorismo como estilo de vida favorece a criação de um ambiente de bem-estar e harmonia com os consumidores. Evidenciou-se, ainda, que o empreendedorismo pode oferecer elevados graus de realização, à medida que permite desenvolver, de modo alinhado, o prazer no e pelo trabalho, como também uma melhoria na qualidade de vida. Além disso, ter no seu negócio um espelho das suas crenças proporciona aos sujeitos uma energia pessoal para despertar em outras pessoas o reflexo da sua ideologia de vida. Os valores sociais enfatizam o sucesso do negócio e constroem planos para o futuro que encaminham para o fortalecimento do negócio.

\subsection{LIMITAÇÕES DA PESQUISA}

Neste trabalho buscou-se contribuir com a base de conhecimento sobre empreendedorismo por estilo de vida, todavia, os resultados desta pesquisa ainda são limitados. Apontou-se primeiramente como uma limitação o fato deste estudo se relacionar à subjetividade da análise qualitativa dos resultados. Em segundo lugar, embora os achados deste trabalho tenham trazido algumas importantes contribuições, destacou-se a limitação relacionada ao fato de o estudo ter sido apenas alicerçado em entrevistas.

A partir dos pontos destacados, cabe a reflexão de investigar se esses achados teriam relação específica com o perfil dos entrevistados ou se poderiam estar presentes em demais amostras de empreendedores do mesmo perfil. Apesar desses limitadores, os resultados poderão servir de incentivo para pesquisas adicionais sobre tópicos relacionados com a motivação de empreender por estilo de vida. 


\subsection{SUGESTÕES DE PESQUISAS FUTURAS}

Sugere-se que futuras pesquisas devam ser realizadas com amostras maiores e em distintas localidades para permitir uma maior riqueza na caracterização dos empreendedores por estilo de vida e aumentar o potencial de generalização das respostas. Destaca-se que teorias e frameworks existentes no campo da Psicologia como, por exemplo, o aplicado neste estudo, podem ser de grande auxilio no entendimento de questões motivacionais do indivíduo.

Assim, encoraja-se que estudiosos interessados nesse tema se valham dos conhecimentos adquiridos por este trabalho para avançar na consolidação do corpo teórico do empreendedorismo. Estudo futuros, por exemplo, poderiam aplicar escalas de mensuração dos diferentes níveis hierárquicos de motivação intrínseca e extrínseca, de forma a permitir uma generalização dos apontamentos do presente estudo.

\section{REFERÊNCIAS}

Allardyce, S. (2015). A continuum approach to lifestyle entrepreneurship. Retrieved from http://openair.rgu.ac.uk

Bardin, L. (2009). Análise de Conteúdo. Lisboa: Edições 70.

Bergamini, C. (1997). A Motivação nas organizações. (4 ed.). São Paulo: Atlas.

Bredvold, R., \& Skålén, P. (2016). Lifestyle entrepreneurs and their identity construction: A study of the tourism industry. Tourism Management, 56(2), 96-105.

Burns, P. (2001). Entrepreneurship and small business. Hampshire, UK: Palgrave Macmillan.

Buttner, E., \& Moore, D.(1997). Women's organizational exodus to entrepreneurship: Self-reported motivations and correlates with success. Journal of Small Business Management, 35(1), 34-46.

Deci, E., \& Ryan, R. (1980). The empirical exploration of intrinsic motivational processes. In L. Berkowitz (Ed.), Advances in Experimental Social Psychology (Vol. 13, pp. 39-80). New York: Academic Press.

Domenico, M. (2003). Lifestyle Entrepreneurs in the Hospitality Sector: Guest House Owner-Occupiers (PhD thesis). University of Strathclyde, Glasgow. 
Etzioni, A. (1996). The responsive community: A communitarian perspective. American Sociological Review, 6, 1-11.

Getz, D., \& Carlsen, J. (2005). Family business in tourism: State of the art. Annals of Tourism Research, 32(1), 237-258.

Golden, B. (1992). The past is the past-or is it? The use of retrospective accounts as indicators of past strategy. Academy of Management journal, 35(4), 848-860.

Gomez-Velasco, M., \& Saleilles, S. (2007). The local embeddedness of lifestyle entrepreneur: An exploratory study. Proceedings of the Interdisciplinary European Conference on Entrepreneurship Research, Montpellier, 5.

Henderson, J. (2002). Building the rural economy with high-growth entrepreneurs. Economic Review, 87(3), 45-70.

Henricks, M. (2002). Not just a living: The complete guide to creating a business that gives you a life. New York: Basic Books.

Jaouen, A., \& Lasch, F. (2013). A new typology of micro-firm owner-managers. Research in Management. France International Small Business Journal, 1(25), 49-76.

Johnson, J. (2001). In-depth interviewing. In J. Gubrium, \& J. Holstein (Orgs.), Handbook of interview research. Context \& method. Thousand Oaks, CA: Sage.

Li, Y., Miao, L., Zhao, X., \& Lehto, X. (2013). When family rooms become guest lounges: Work-family balance of $B \& B$ innkeepers. International Journal of Hospitality Management, 34, 138-149.

Marcketti, S. (2006). An Exploratory Study of Lifestyle Entrepreneurship and Its Relationship to Life Quality. Family and Consumer Sciences Research Journal, 34(3), 241-259.

Moore, C. (1986). Understanding entrepreneurial behavior: A definition and model. Academy of Management, 1, 66-70.

Murry, H. (2002). Predictors of multi-dimensional well-being in women entrepreneurs: Family/ business demands and sense of coherence (Doctoral thesis). University of Wisconsin, Madison. 
Peters, M., Frehse, J., \& Buhalis, D. (2009). The importance of lifestyle entrepreneurship: A conceptual study of the tourism industry. PASOS-Revista de Turismo y Patrimônio Cultural, 7(2), 393-405.

Ribeiro, A., \& Krakauer B. (2016). Empreendedorismo por estilo de vida: Estudo exploratório sobre fatores motivacionais, características e gestão. Revista de Gestão e Secretariado, $7(1), 112-131$.

Shane, S., \& Venkataraman, S. (2000). The promisse of entrepreneurship as a field of research. Academy of Management Review, 25(1), 217-226.

Valente, F. (2018). Empreendedorismo estilo de vida: Uma realidade diferente? Anais das Jornadas Luso-Espanholas de Gestão Científica, Guarda, Portugal, 28.

Vallerand, R. (1997). Toward a hierarchical model of intrinsic and extrinsic motivation. In Advances in experimental social psychology, 29, 271-360).

Welter, F., Baker, T., Audretsch, D., \& Gartner, W. (2017). Everyday entrepreneurship: A call for entrepreneurship research to embrace entrepreneurial diversity. Entrepreneurship Theory and Practice, 41(3), 311-321.

\section{Como citar este artigo:}

\section{ABNT}

BOZZO, Andrea Luisa et al. Ideologia de vida e motivação empreendedora. RACE, Revista de Administração, Contabilidade e Economia, Joaçaba: Editora Unoesc, v. 18, n. 2, p. 281-298, maio/ago. 2019. Disponível em: http://editora.unoesc.edu.br/index.php/race. Acesso em: dia/mês/ano.

\section{APA}

Bozzo, A. L., Freitas, H. M., Martens C. D. P., \& Santana, A. D. S. (2019). Ideologia de vida e motivação empreendedora. RACE, Revista de Administração, Contabilidade e Economia, 18(2), 281-298. Recuperado de http://editora.unoesc.edu.br/index.php/race 
